\section{Las ceremonias del silencio: una experiencia poética}

A Francisco Ruiz Udiel
Por: Víctor Ruiz

(c) UNAN-Managua Recibido: mayo 2016 Aprobado: junio 2016

En mi experiencia poética con Las ceremonias del silencio de Ana llce Gómez, muchas veces me he preguntado las razones por las que constantemente vuelvo a las páginas de este poemario. Debo confesar que pocos son los libros de poesía nicaragüense a los que regreso con esa misma pasión del primer encuentro, leer es tan necesario como respirar, pero es un acto de amor el que nos conduce nuevamente a la intimidad de la relectura. De esa primera experiencia me quedó la impresión de que Las ceremonias del silencio reivindicaba una poesía que exaltaba la rebelión interior frente al trepidante bullicio exterior, con este libro Ana Ilce Gómez se sumaba a esa tribu de poetas silenciosos como Carlos Martínez Rivas y su Insurrección solitaria, Ernesto Mejía Sánchez y Ensalmos y conjuros, Álvaro Urtecho y su Cantata estupefacta, y un poco más cercanos, pero no por eso menos importantes: Alejandra Sequeira y su Quien me espera no existe, Francisco Ruiz Udiel y ese canto desgarrado en Alguien me ve llorar en un sueño. Poetas de profundidad emocional, J. M. Cohen diría que en ellos no hay "una exploración superficial de la naturaleza o de la sociedad, sino un descenso a las profundidades de su propio corazón". El tiempo y el yo son los temas principales de estos autores. De ahí entonces que un ya lejano artículo sobre la poesía de Ana llce Gómez, Beltrán Morales dijera que:

"Las ceremonias del silencio bien pudo llamarse Las ceremonias del amor o Las ceremonias del tiempo. A ese grado resaltan en el poemario la eternidad del tiempo y la fugacidad del amor."

El tiempo, el amor, la mujer y la poesía, vistos no como motivos comunes a todo poeta o individuo, sino como experiencia personal; la poesía de Ana llce Gómez está más emparentada con los poetas de la meditación que con la tradición literaria hispanoamericana; en ella está ausente la exuberancia verbal de Neruda, la dislocación sintáctica de Vallejo y la maquinaria metafórica de Huidobro; lo que caracteriza su estilo es la austeridad y precisión léxicas. En Las ceremonias del silencio la palabra se encuentra en comunión con el pensamiento, y será esto lo que precisamente defina su poesía: leer a Ana llce Gómez es entrar a un espacio poético en el que se nos revela un conocimiento, una experiencia, en ella se cumple lo que Gastón Bachelard nos dice sobre el instante poético:

"La poesía es una metafísica instantánea. En un breve poema, debe dar una visión del universo y el secreto de un alma, un ser y unos objetos, todo al mismo tiempo. Si sigue simplemente el tiempo de la vida, es menos que la vida; solo puede ser más que la vida inmovilizando la vida, viviendo en el lugar de los hechos la dialéctica de las dichas y de las penas." (Gastón Bachelard-La intuición del instante) 
Por eso es que la poesía de Ana Ilce Gómez tiende más al silencio que al furor verbal, porque solo en el silencio se puede dar ese viaje hacia la interioridad, de donde saldrá esa visión personal del tiempo, el amor, la mujer y la poesía, es decir, esa visión del universo al que aludía Bachelard. Poética de la meditación y de la experiencia, Las ceremonias del silencio está teñida por ese halo reflexivo que encontramos en poetas como Dickinson, Yeats, Rilke, Eliot, Antonio Machado, Cernuda, Biedma, entre otros... Para estos autores el acto poético es una forma de autoconocimiento, de ahí que el monólogo sea el recurso preferido para bucear en las aguas oscuras del pensamiento.

En "De sombras y soles incendiada", que para mí es su ars poética, Ana Ilce resume los temas obsesivos que permearán su poesía: Cuando yo era una muchacha cabellos al viento, ojo descubriendo apenas el borde la luz de la mañana, de labios romos y diente no afilado por el dolor de las palabras.

Cuando mis pies sólo sabían de las calles polvorientas de mi pueblo, y mi corazón como un río detenido se asomaba a la vida y la miraba allá lejos deslizarse, correr entre los hombres, apretujarse amorosa contra el tiempo, o subir a los árboles desde donde caía lentamente como un pájaro ahogado sobre los grandes charcos de la tarde.

Cuando mi edad era tan sólo una palabra, un invierno debatiéndose triunfante contra el moho, y en mi pecho no había más cabida sino para un amor tranquilo como el agua tranquila de los pozos.

Entonces no presentía en mí la mano que comenzaba a dibujar el canto, ni el pie desesperado trazando surcos de vida para el hombre, ni a esta mujer que hoy soy, de sombras y soles incendiadas, sitiada por el fuego del amor, ulcerada por la pasión de la palabra.

Como se observa en el primer verso el "yo" es el epicentro de la evocación poética, lo que se nos presenta luego es el resultado de ese auscultar en la interioridad y en el paso del tiempo. En la primera estrofa se nos da la imagen de esa muchacha que al descubrir la luz de la mañana descubre también el dolor de las palabras, es decir, de la poesía. En la segunda estrofa la misma muchacha ahora se asoma a la vida y conoce el amor, apretujada a este se rebela contra el tiempo. En la tercera estrofa encontramos el motivo de la palabra y del amor, no hay diferencia entre ellos: tanto el acto del amor como el de la poesía son armas contra el moho o el tiempo. De ahí que en la cuarta estrofa, que es un regreso al instante de la evocación, el yo de la primera estrofa se nos presenta como la mujer que dibujaba el canto y trazaba las líneas del amor, estas dos acciones son las que configuran su yo actual, es decir, la mujer que se ve en el pasado y reconoce que su vida ha estado sitiada por "por el fuego del amor, / ulcerada por la pasión de la palabra". Como vemos, básicamente los temas de este poema son el tiempo y el yo, subordinados a estos: el amor, la mujer, la poesía.

En "Esa mujer que pasa", poema enigmático por su reticencia, se plantea una serie de preguntas que indagan sobre la identidad mujer que pasa:

¿Quiénesestamujer quepasa, estasombra, estanoche?

¿Quién conoce su nombre? ¿Quién la nombra del otro lado de la nada para nada?

¿Quién es esta mujer que pasa y no deja nada de sí?

Sólo su paso rueda en la noche, Sólo su voz. 
El énfasis en el acto de pasar y los dos versos finales nos dan la clave para la revelación poética: la mujer se mueve en el tiempo, es el tiempo que la nombra del otro lado de la nada para nada, porque el tiempo es el gran anonimizador, nos borra los nombres y la identidad, sin embargo esta mujer que pasa deja algo tras de sí: su voz, su poesía, y esto es lo que la define, lo que le da identidad.

En otro poema, "El amor viene conmigo", la poeta vuelve al monólogo, al yo retrospectivo y a esos temas constantes en su poesía: el tiempo y el amor:

"Desde lejanos tiempos el amor viene conmigo. / Como un gato silencioso / me viene persiguiendo a través / de tardes hueras y cenagosos días." El amor se presenta como un sentimiento constante en todos los momentos de su vida, pero no es algo que se llama, sino que se impone como una condición inherente a la vida, el amor también es visto como una dualidad,

"...el amor es doble: es la suprema ventura y la desdicha suprema" nos dice Octavio Paz, o, como dice Ana Ilce Gómez, es canto de gloria y honra fúnebre.

La conciencia de la transitoriedad del tiempo y el amor confiere a los poemas de Ana llce Gómez una actitud escéptica frente a la vida. "Calle de verano", "Carta" y "Ella, la recién nacida" son claros ejemplos de esta característica. En el primer poema tenemos como protagonistas a unos niños vistos desde su infancia y desde su vejez, el paso del tiempo se evidencia a partir de la enumeración caótica, en esta enumeración el tiempo transcurre y el alma se pone del color de la tierra, la tarde se encorva y la cal del aire blanquea las sienes (de los niños), la vida es un animal muerto tendido bajo el cielo, el tiempo ha transcurrido y ha barrido con ella la infancia de los niños, ahora ellos regresan bajo el mismo arco de la tarde del que partieron, al final lo que queda son piedras. En "Carta" el protagonista es el amor, este se presenta como un acontecer doloroso porque es arrastrado por el tiempo que es la marejada que todo lo arrastra y lo sepulta en el olvido. En "Ella, la recién nacida", la muerte es vista como nacimiento, un reino de luz, al contrario la vida es considerada una "honda noche que se alarga".

Ese triunfo de la muerte sobre la vida o, mejor dicho, del tiempo sobre la voluntad de vivir aparece más claramente en el poema "Letra viva":

Vamos en viaje con la vida. Todos adultos y yo como pollo recién salido de la cáscara. Venimos de un punto harto verdadero a errar a esta calle imaginaria. Y no, no resucitaremos como Lázaro. Atrás el profeta, la sibila délfica, y el nigromante porque sólo ha de triunfar la zarpa y el dentellazo puro de la muerte. Entre tanto a mí dénme el reposo, el hosco sello de mujer con el hombro que sostenga la poronga de agua nueva y recién hecha. Que al fin y al cabo, nuestro único será esto: El horror a la fosa común, la espalda inadecuada para el golpe que nos ha de partir.

Como vemos, la vida es viaje por una calle imaginaria (concepción cristiana de la vida, por tanto, escéptica) en el que lo único que triunfa es la muerte y la único dominio que tenemos en la vida es la certeza de la muerte y el miedo que le profesamos a la tumba.

No obstante, Las ceremonias del silencio también refleja una lucha contra las furias y penas del tiempo. Octavio Paz, en uno de los mejores poemas que se han escrito sobre la rebelión del amor, nos dice: 
... amar es combatir, si dos se besan el mundo cambia, encarnan los deseos, el pensamiento encarna, brotan alas en las espaldas del esclavo... amar es combatir, es abrir puertas, dejar de ser fantasma con un número a perpetua cadena condenado por un amo sin rostro;

(Octavio Paz-Piedra de sol)

A su vez Ana Ilce Gómez en "Reloj de arena" dice:

Medir el tiempo es el quehacer de los que no han amado.

Yo olvidé la arena que caía grano a grano a grano.

Así cumplí con el amor. Si se me llega la hora no sabré si es mi llegada o mi partida, sólo sé que sin treguas en la vida pagué lo que el dios de fuego me cobró.

En este poema la vida sin amor no es más que un esperar que el tiempo nos arrastre al abismo de la muerte. Amar nos redime de la transitoriedad y las largas cadenas del "tiempo carnicero" que se precipita "grano a grano a grano" sobre nuestros cuerpos. "Somos tiempo y no podemos substraernos a nuestro dominio" nos sigue diciendo Paz, pero amar "es una victoria contra el tiempo", es ese instante en el que tomamos conciencia de la fugacidad de la vida y del amor, por eso es que la poeta "sin tregua en la vida / pagué lo que el dios de fuego /me cobró"

En "Extraña multitud" el amor es sospechoso de un crimen:

Los ojos de esa extraña multitud persiguiéndome en la noche cerrándome los sitios acusándome de haber cometido el amor.

La plena conciencia del paso del tiempo y la fugacidad de la vida confiere al ser su condición de libertad. Los amantes son sospechosos porque se saben libres, al amar saben que han iniciado una lucha contra el tiempo, se saben dueños de esa pequeña porción que el dios del fuego les otorga. De ahí que la extraña multitud, esos seres anónimos que cuentan su vida grano a grano y están sujetos al "tiempo carnicero", los persigan, cierren y acusen.

En Ana Ilce Gómez también hay plena conciencia de su condición de poeta. Más que un don, la poesía aparece como un padecimiento dichoso: 
Victor Ruiz Ceremonias del silencio:una experiencia.. pp. 31-35

El poema es una puerta por donde se cuelan adioses

aguaceros testamentos de amor y rencores tiernos.

El poema puede ser un abismo

Un racimo de espaldas

Una medusa amenazante en el fondo de su mar.

Sólo hay que saber cuándo adueñarse de esa luz

O quedar ciegos para siempre.

En el poema puede filtrarse la celebración del amor o los "rencores tiernos" que este nos deja en su testamento. El poema puede ser entonces una oda llena de luz o una elegía que "nos ciega para siempre". En el último poema de Las ceremonias del silencio, la poeta echa andar a sus poemas al mundo, porque no será ni su nombre ni rostro lo que la definirán después de su muerte, sino su voz. La poesía también es una lucha contra el tiempo porque en ella actúa el instante de la creación y el instante de la lectura. En el acto poético el poeta se inmortaliza porque sabe que de alguna manera ese intervalo en el que fue concebido el poema será revivido en la lectura de unos labios anónimos, por eso es que Ana Ilce Gómez cierra este bello poemario con estas palabras que son un canto de amor a la poesía: "No moriré al morirme". 